\title{
The Role of Platelet Counts in the Assessment of Inpatient Women With Preeclampsia
}

\author{
Samara Laskin,, ${ }^{1,2}$ Beth Payne, BSc, ${ }^{1,3}$ Jennifer A. Hutcheon, PhD, ,3,4 Ziguang Qu, BASc,,3 \\ M. Joanne Douglas, MD, FRCPC, ${ }^{5}$ Jason Ford, MD, FRCPC, ${ }^{2}$ Tang Lee, MSc, ${ }^{1,3}$ \\ Laura A. Magee, MD, FRCPC, MSc, ${ }^{1,3,4,6}$ Peter von Dadelszen, MBChB, DPhil, FRCSC ${ }^{1,3,4}$; \\ for the PIERS (Pre-eclampsia Integrated Estimate of RiSk) Study Group \\ 1'Department of Obstetrics and Gynaecology, University of British Columbia, Vancouver BC \\ ${ }^{2}$ Department of Pathology and Laboratory Medicine, University of British Columbia, Vancouver BC \\ ${ }^{3}$ The CFRI Reproduction and Healthy Pregnancy Cluster, University of British Columbia, Vancouver BC \\ ${ }^{4}$ School of Public and Population Health, University of British Columbia, Vancouver BC \\ ${ }^{5}$ Department of Anesthesiology, Pharmacology and Therapeutics, University of British Columbia, Vancouver BC \\ ${ }^{6}$ Department of Medicine, University of British Columbia, Vancouver BC
}

\section{Abstract}

Objective: Platelet count has been proposed as a screening test for generalized coagulopathy in women with preeclampsia. We performed this study to determine the relationship between platelet counts and the risk of abnormal coagulation and adverse maternal outcomes in women with preeclampsia.

Methods: We used data from women in the PIERS (Pre-eclampsia Integrated Estimate of RiSk) database. Abnormal coagulation was defined as either an international normalized ratio result greater than and/or a serum fibrinogen level less than the BC Women's Hospital laboratory's pregnancy-specific normal range. The relationship between platelet counts and adverse maternal outcomes was explored using a logistic regression analysis. The sensitivity, specificity, positive predictive value, and negative predictive value of platelet counts in identifying abnormal coagulation or adverse maternal outcomes were calculated.

Results: Abnormal coagulation occurred in 105 of 1405 eligible women $(7.5 \%)$. The odds of having abnormal coagulation were increased for women with platelet counts < $50 \times 10^{9} / \mathrm{L}$ (OR 7.78; $95 \% \mathrm{Cl} 3.36$ to 18.03 ) and between 50 and $99 \times 10 \%$ L (OR 2.69; $95 \% \mathrm{Cl} 1.44$ to 5.01 ) compared with women who had platelet counts above $150 \times 10^{9} / \mathrm{L}$. Platelet counts $<100 \times 10^{9} / \mathrm{L}$ were associated with significantly increased odds of adverse maternal outcomes, most specifically blood transfusion. A platelet count of $<100 \times 10^{9} / \mathrm{L}$ had good specificity in identifying abnormal coagulation and adverse maternal outcomes $(92 \%$ [95\% Cl $91 \%$ to $94 \%$ ] and $92 \%$ [95\% Cl $91 \%$ to $94 \%$ ], respectively), but poor sensitivity $(22 \%[95 \% \mathrm{Cl} 15 \%$ to $31 \%]$ and $16 \%[95 \% \mathrm{Cl}$ $11 \%$ to $23 \%$ ], respectively).

Key Words: Preeclampsia, adverse outcomes, coagulation, platelets

Competing Interests: None declared.

Received on February 1, 2011

Accepted on March 31, 2011
Conclusion: A platelet count $<100 \times 10^{9} / \mathrm{L}$ is associated with an increased risk of abnormal coagulation and maternal adverse outcomes in women with preeclampsia. However, the platelet count should not be used in isolation to guide care because of its poor sensitivity. Whether or not a platelet count is normal should not be used to determine whether further coagulation tests are needed.

\section{Résumé}

Objectif : Le recours à la numération plaquettaire a été proposé à titre de test de dépistage visant la coagulopathie généralisée chez les femmes qui présentent une prééclampsie. Nous avons mené cette étude pour déterminer la relation entre les numérations plaquettaires et le risque de coagulation anormale et d'issues maternelles indésirables chez les femmes qui présentent une prééclampsie.

Méthodes : Nous avons utilisé des données issues de participantes à la base de données PIERS (Pre-eclampsia Integrated Estimate of RiSk). La coagulation anormale a été définie comme étant un résultat de rapport international normalisé se situant au-delà de la plage normale propre à la grossesse du laboratoire du BC Women's Hospital et/ou comme étant un taux sérique de fibrinogène se situant en deçà de cette plage. La relation entre les numérations plaquettaires et les issues maternelles indésirables a été explorée au moyen d'une analyse de régression logistique. La sensibilité, la spécificité, le coefficient de prévision d'un test positif et le coefficient de prévision d'un test négatif propres aux numérations plaquettaires pour ce qui est de l'identification d'une coagulation anormale ou d'issues maternelles indésirables ont été calculés.

Résultats : Une coagulation anormale s'est manifestée chez 105 des 1405 femmes admissibles (7,5\%). Les risques de présenter une coagulation anormale étaient accrus chez les femmes qui comptaient des numérations plaquettaires $<50 \times 10^{9} / 1$ $(\mathrm{RC}, 7,78$; IC à $95 \%, 3,36-18,03)$ et se situant entre 50 et $99 \times 10^{9} / \mathrm{l}(\mathrm{RC}, 2,69$; IC à $95 \%, 1,44-5,01)$, par comparaison

J Obstet Gynaecol Can 2011;33(9):900-908 
avec les femmes qui comptaient des numérations plaquettaires se situant au-delà de $150 \times 10 \%$. Les numérations plaquettaires $<100 \times 10^{9} /$ ont été associées à une hausse significative des risques de connaître des issues maternelles indésirables, plus particulièrement une transfusion sanguine. Une numération plaquettaire $<100 \times 10^{9} / /$ présentait une bonne spécificité pour ce qui est de l'identification d'une coagulation anormale et d'issues maternelles indésirables (92\% [IC à $95 \%, 91 \%$ - 94\%] et $92 \%$ [IC à $95 \%, 91 \%$ - $94 \%$ ], respectivement), mais une faible sensibilité $(22 \%$ [IC à $95 \%, 15 \%-31 \%$ ] et $16 \%$ [IC à $95 \%, 11 \%-23 \%$ ], respectivement).

Conclusion : Une numération plaquettaire $<100 \times 10^{9} / /$ est associée à un risque accru de coagulation anormale et d'issues maternelles indésirables chez les femmes qui présentent une prééclampsie. Toutefois, la numération plaquettaire ne devrait pas être utilisée de façon isolée pour orienter les soins, et ce, en raison de sa faible sensibilité. Le caractère normal ou non d'une numération plaquettaire ne devrait pas être utilisé pour déterminer si la tenue d'autres tests de coagulation s'avère requise.

\section{INTRODUCTION}

$\mathrm{P}$ reeclampsia is a complex, multi-system disorder that remains a significant cause of maternal morbidity and mortality worldwide. ${ }^{1}$ Preeclampsia seems to result from a mismatch between fetoplacental demands and the ability of the maternal uterine blood supply to meet those demands, which leads to the release of vasoactive and innate immune activating substances in the maternal circulation, with subsequent endothelial and innate immune activation. ${ }^{2,3}$ This leads to maternal clinical manifestations, which include hypertension, renal and hepatic dysfunction, systemic inflammation, and hematological abnormalities. These hematological abnormalities usually manifest as mild and indolent consumptive coagulopathies, including consumption of platelets, clotting factors, and fibrinogen. Occasionally, these abnormalities become severe, for example manifesting as disseminated intravascular coagulation, which can be life-threatening., ${ }^{3,4}$

The care of women with preeclampsia should be based on the goal of reducing maternal and perinatal risks, two priorities that may be in conflict remote from term. Several studies have supported the use of a platelet count threshold $\left(100 \times 10^{9} / \mathrm{L}\right)$ above which even women with

\section{ABBREVIATIONS}

aPTT activated partial thromboplastin time

BP blood pressure

dBP diastolic blood pressure

HELLP hemolysis, elevated liver enzymes, and low platelet

INR international normalized ratio

PIERS Pre-eclampsia Integrated Estimate of RiSk

sBP

systolic blood pressure severe preeclampsia are unlikely to have abnormalities in aPTT, INR, or serum fibrinogen..$^{5-7}$ This threshold has been endorsed by the Society of Obstetricians and Gynaecologists of Canada in the absence of placental abruption. ${ }^{8}$ Standardized assessment and surveillance guidelines in British Columbia include the aforementioned laboratory assessments of coagulation, but recommend that aPTT, INR, and serum fibrinogen be measured in every woman with suspected or confirmed preeclampsia; this regimen of investigation is associated with reduced maternal risk. ${ }^{9,10}$ Coagulation tests, which are expensive, are generally used to identify bleeding risk prior to Caesarean section or vaginal birth in order to avoid maternal hemorrhage, as well as to identify the risk of epidural hematoma in women requesting neuraxial blockade. ${ }^{11}$

The purpose of this study was to determine the relationship between platelet count and the risk of an abnormal coagulation test (INR or serum fibrinogen) in women with preeclampsia. A secondary aim was to establish the relationship between platelet count or the occurrence of one or more abnormal coagulation test results with blood transfusion and/or other elements of a combined adverse maternal outcome within 48 hours of hospital admission.

\section{METHODS}

The data used for this study were extracted from PIERS database. PIERS is a prospective study of women with preeclampsia admitted to tertiary obstetric centres in which there is a general policy of expectant management of preeclampsia remote from term. Full details of the PIERS methodology have been published elsewhere. ${ }^{12}$ Data were collected on women admitted from September 2003 to January 2010 to eight tertiary perinatal centres: four in Canada, two in the United Kingdom, one in New Zealand, and one in Australia. In four sites, until September 2007, women were required to give informed consent for enrolment in PIERS. In three of those four sites (after September 2007), and in all other sites since joining the study, PIERS was conducted as a continuous quality improvement project. The continuous quality improvement project entailed the introduction of predetermined guidelines for the initial assessment and ongoing surveillance of women admitted to hospital with suspected or confirmed preeclampsia. The details of these guidelines have been published elsewhere., ${ }^{9,10}$

Women were included in the PIERS study if they met any one of the following inclusion criteria: (1) $\mathrm{BP} \geq$ $140 / 90 \mathrm{mmHg}$ (on at least two occasions $\geq 4$ hours apart after 20 weeks' gestation, by any method in the hospital) 


\begin{tabular}{|c|c|c|c|}
\hline Characteristic & $\begin{array}{l}\text { Abnormal coagulation* } \\
(n=105 \text { women })\end{array}$ & $\begin{array}{l}\text { Normal coagulation } \\
(n=1300 \text { women })\end{array}$ & $P^{\star *}$ \\
\hline \multicolumn{4}{|l|}{ Demographics (within $48 \mathrm{~h}$ of eligibility) } \\
\hline Maternal age at EDD (years), median (interquartile range) & 30 (26 to 34$)$ & $32(28$ to 36$)$ & 0.004 \\
\hline Gestational age at eligibility (weeks), median (interquartile range) & 32.7 (30.3 to 36.7$)$ & $36.4(33.4$ to 38.4$)$ & $<0.001$ \\
\hline Gestational age at eligibility < 34 weeks, n (\%) & $59(56.2)$ & $362(27.8)$ & $<0.001$ \\
\hline Parity $\geq 1, \mathrm{n}(\%)$ & $30(28.6)$ & $354(27.2)$ & 0.767 \\
\hline Smoking in this pregnancy, $\mathrm{n}(\%)$ & $15(14.3)$ & $138(10.6)$ & 0.336 \\
\hline \multicolumn{4}{|l|}{ Preeclampsia description } \\
\hline Hypertension and proteinuria, n (\%) & $76(72.4)$ & $841(64.7)$ & 0.321 \\
\hline Hypertension and hyperuricaemia, n (\%) & $11(10.5)$ & $212(16.3)$ & \\
\hline \multicolumn{4}{|l|}{ Peak blood pressure $(\mathrm{mmHg})$} \\
\hline Mean arterial pressure, median (interquartile range) & $121.3(115.2$ to 130.0$)$ & $121.3(115.0$ to 130.0$)$ & 0.799 \\
\hline sBP, median (interquartile range) & $161(150$ to 180$)$ & $162(151$ to 178$)$ & 0.534 \\
\hline $\mathrm{dBP}$ & 103 (100 to 110$)$ & 102 (98 to 110$)$ & 0.740 \\
\hline Worst dipstick proteinuria, median (interquartile range) & 2 (1 to 3$)$ & 2 (1 to 3$)$ & 0.911 \\
\hline Highest aspartate transaminase, median (interquartile range) & 37.5 (22 to 84.5$)$ & 29 (22 to 42$)$ & 0.002 \\
\hline \multicolumn{4}{|l|}{ Interventions } \\
\hline Corticosteroid administration, $\mathrm{n}(\%)$ & $46(43.8)$ & $348(26.8)$ & $<0.001$ \\
\hline Antihypertensive medications administered, $\mathrm{n}(\%)$ & $78(74.3)$ & $880(67.7)$ & 0.163 \\
\hline Birth weight $<3$ rd percentile ( $\mathrm{n}$ babies) $(41), \mathrm{n}(\%)$ & $9(8.6)$ & $109(8.4)$ & 0.949 \\
\hline Intrauterine fetal death ( $\geq 20+0 \mathrm{wk}$ and/or $\geq 500 \mathrm{~g}), \mathrm{n}(\%)$ & $1(0.9)$ & $12(0.9)$ & 0.976 \\
\hline Neonatal death (before 28d), n (\%) & $2(1.9)$ & $14(1.1)$ & 0.442 \\
\hline Infant death prior to hospital discharge or $6 \mathrm{wk}, \mathrm{n}(\%)$ & $2(1.9)$ & $17(1.3)$ & 0.611 \\
\hline
\end{tabular}

*Elevated INR, and/or decreased fibrinogen, compared with normal third trimester range.

${ }^{* *} P$ calculated using Mann-Whitney $U$ for continuous variables and Fisher exact test for categorical except preeclampsia description, which used chi-squared test EDD: expected date of delivery

and either proteinuria (of $\geq 2+$ by dipstick, $\geq 0.3 \mathrm{~g} / \mathrm{d}$ by 24 -hour urine collection, or $>30 \mathrm{mg} / \mathrm{mmol}$ by spot urinary protein:creatinine ratio) or hyperuricemia (greater than local upper limit of normal for non-pregnant individuals); (2) HELLP syndrome even in the absence of hypertension or proteinuria; or (3) superimposed preeclampsia, defined as pre-existing hypertension with accelerated hypertension (as diagnosed by the clinician, or defined as a $\mathrm{sBP} \geq 170 \mathrm{mmHg}$ or $\mathrm{dBP} \geq 120 \mathrm{mmHg}$ ), new proteinuria, or new hyperuricemia. Women were excluded if they were admitted in active labour or if they achieved any component of the maternal outcome prior to collection of predictors. This inclusive definition was chosen to reflect the variable and multisystem nature of preeclampsia seen in clinical practice. ${ }^{13-15}$

The list of adverse maternal outcomes recorded by PIERS was developed by iterative Delphi consensus ${ }^{16,17}$ and includes maternal mortality and any of the following maternal morbidities: hepatic dysfunction, hematoma, or rupture; eclampsia; Glasgow Coma Scale score < 13; stroke; reversible ischemic neurological deficit; transient ischemic 


\begin{abstract}
Platelet versus predicted probability of abnormal coagulation (INR and/or fibronogen). Platelet count range of 100 to $150 \times 10 \%$ indicated by vertical bars and grey shaded area. The points on the graph represent the average observed porbability for each platelet count $\times 10^{\%} / \mathrm{L}$. The solid line represents the expected probability of outcome based on a logistic regression model with platelet count fitted as a restricted cubic spline with 5 knots.
\end{abstract}

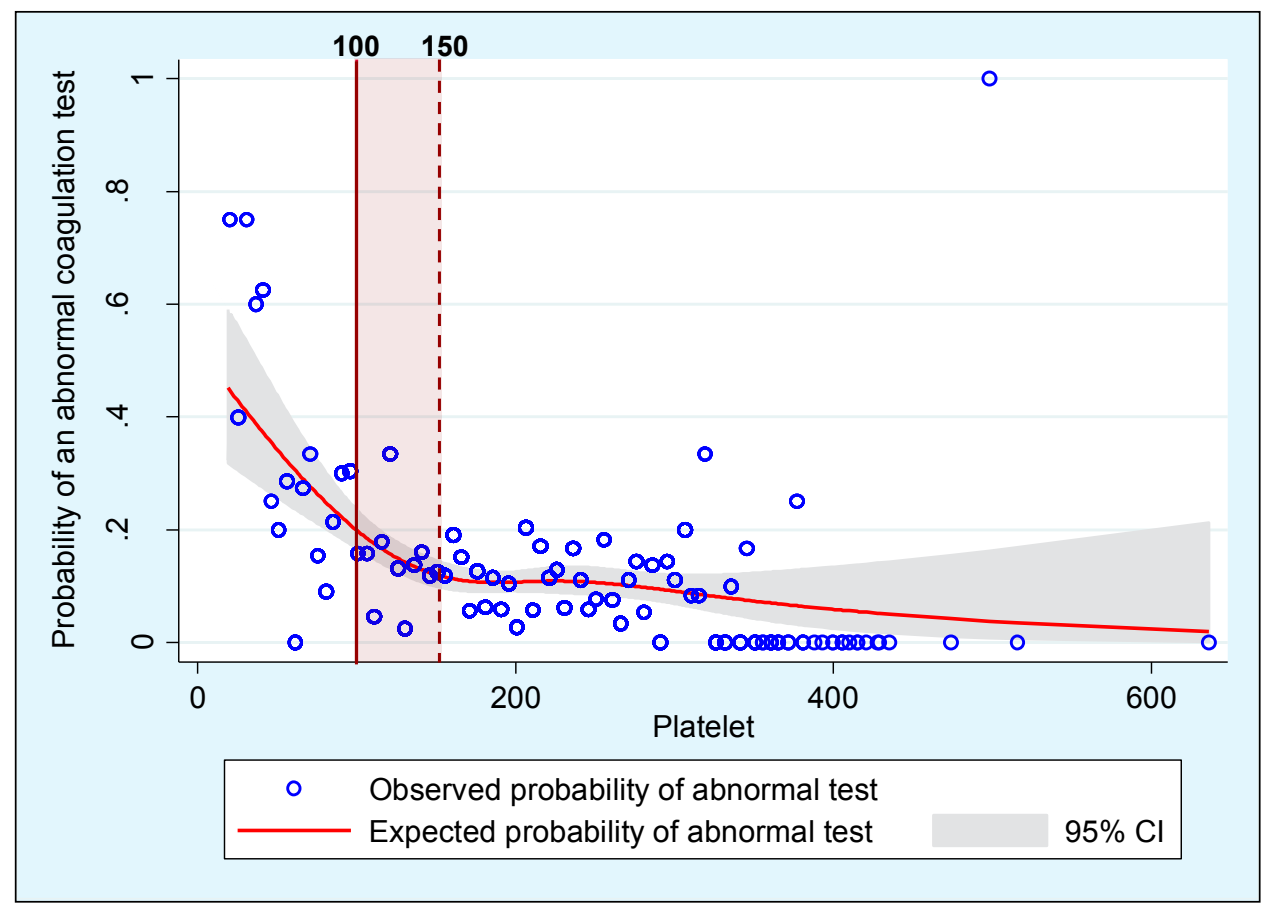

attack; posterior reversible encephalopathy; cortical blindness or retinal detachment; need for positive inotrope support; infusion of a third parenteral antihypertensive; myocardial ischemia or infarction; acute renal insufficiency (in women without prior renal disease) ${ }^{18}$; acute renal failure (in women with prior renal disease) ${ }^{18}$; dialysis; pulmonary edema; oxygen saturation by pulse oximetry $<90 \%$; requirement of $\geq 50 \% \mathrm{FiO}_{2}$ for $>1$ hour; intubation (other than solely for Caesarean section); placental abruption; and transfusion of any blood product.

The lowest platelet count within 48 hours of eligibility was used for analysis. For women with an adverse outcome, the lowest value prior to the occurrence of an adverse outcome was used. Abnormal coagulation was defined as an INR result greater than and/or a serum fibrinogen level less than the third trimester pregnancy ranges at the BC Women's Hospital and Health Centre in British Columbia. These threshold levels are INR $>1.06$ and serum fibrinogen $<3.54 \mathrm{~g} / \mathrm{L}$. Only women with a platelet count and recorded values for INR and fibrinogen within 12 hours of their relevant platelet count were included in the study. We excluded aPT'T from the definition of this outcome because of the high proportion of patients in whom the test was never performed and also because of the possibility that aPTT could be prolonged by the presence of antiphospholipid antibodies or high doses of heparin given for thromboprophylaxis.

The demographics of women with or without abnormal coagulation were compared using a Mann-Whitney $U$ test for continuous variables and a Fisher exact test for categorical variables, except in the case of the description of preeclampsia, for which a chi-squared test was used. To explore the possibility of a non-linear relationship between platelet count and abnormal coagulation, platelet count was modeled as a restricted cubic spline with 5 knots. This allowed a smooth, curvilinear relationship to be generated, which was used to identify logical threshold values for further analysis. Threshold values of $100 \times 10^{\circ} / \mathrm{L}$ and $50 \times 10^{\circ} / \mathrm{L}$ were also analyzed to be consistent with current clinical practice. The occurrence of each abnormal coagulation test result, any adverse maternal outcome within 48 hours of eligibility for the study, and the need for blood transfusion were assessed using logistic regression. The regression models generated for this study were univariable, and included only platelets or abnormal coagulation as individual predictors. For platelets, the variables were entered into the regression model as 


\begin{tabular}{|c|c|c|c|c|}
\hline \multirow[b]{3}{*}{ Outcome } & \multicolumn{4}{|c|}{ Platelet count $\left(\times 10^{9} / \mathrm{L}\right)$} \\
\hline & $<50$ & 50 to 99 & 100 to 149 & $\geq 150$ \\
\hline & 27 & 95 & 273 & 1010 \\
\hline \multicolumn{5}{|c|}{ Abnormal coagulation* } \\
\hline $\mathrm{n}(\%)$ & $9(33.3)$ & $14(14.7)$ & $21(7.7)$ & $61(6.0)$ \\
\hline OR $(95 \% \mathrm{Cl})$ & $\begin{array}{c}7.78 \dagger \\
\text { (3.36 to } 18.04)\end{array}$ & $\begin{array}{c}2.69 \dagger \\
(1.44 \text { to } 5.02)\end{array}$ & $\begin{array}{c}1.30 \\
(0.78 \text { to } 2.17)\end{array}$ & reference \\
\hline \multicolumn{5}{|c|}{ Adverse maternal outcome } \\
\hline $\mathrm{n}(\%)$ & $15(55.5)$ & $9(9.5)$ & $26(9.5)$ & $102(10.1)$ \\
\hline OR $(95 \% \mathrm{Cl})$ & $\begin{array}{c}11.32 \dagger \\
\text { (5.19 to } 24.68)\end{array}$ & $\begin{array}{c}2.21 \dagger \\
(1.36 \text { to } 3.58)\end{array}$ & $\begin{array}{c}1.29 \\
(0.90 \text { to } 1.85)\end{array}$ & reference \\
\hline \multicolumn{5}{|l|}{ Blood transfusion } \\
\hline $\mathrm{n}(\%)$ & $12(44.4)$ & $7(7.4)$ & $10(3.7)$ & $31(3.1)$ \\
\hline OR $(95 \% \mathrm{Cl})$ & $\begin{array}{c}25.27 \dagger \\
\text { (10.92 to } 58.47)\end{array}$ & $\begin{array}{c}2.51 \dagger \\
(1.08 \text { to } 5.87)\end{array}$ & $\begin{array}{c}1.20 \\
(0.58 \text { to } 2.48)\end{array}$ & reference \\
\hline
\end{tabular}

multiple dummy variables, one for each platelet range, with the highest range $\left(>150 \times 10^{\circ} / \mathrm{L}\right)$ used as the reference group. Abnormal coagulation was assessed as a categorical variable that was based on the patient either meeting or not meeting our research definition for abnormal coagulation. We assessed the diagnostic value of different platelet count thresholds by calculating sensitivity, specificity, positive predictive value, and negative predictive value. Statistical analyses were performed using STATA version 10.0 or SPSS version 18.0 (IBM Corp., Somers NY)

Research Ethics Board approval was obtained at all sites.

\section{RESULTS}

Of the 2023 women in the PIERS cohort, 1405 (69.5\%) were eligible for this study. Of the 1405 included here, a total of $122(8.7 \%)$ women had a platelet count $<100 \times 10^{9} / \mathrm{L}$, and 105 women $(7.5 \%)$ had abnormal coagulation as defined by an abnormal INR, serum fibrinogen, or both, on the same blood sample as the worst platelet count. Of those 105 women, $23(21.9 \%)$ had a platelet count $<100 \times 10^{9} / \mathrm{L}$. In total, $152(10.8 \%)$ women had one or more adverse maternal outcomes during their hospital stay. The most common adverse outcomes were a need for blood transfusion, which occrred in 60 women $(4.3 \%)$ and pulmonary edema, which occurred in 35 women $(2.5 \%)$. A full list of the PIERS adverse maternal outcomes and rates within the cohort can be found elsewhere. ${ }^{19}$

The baseline characteristics of the women included in the study with and without abnormal coagulation test results are shown in Table 1 . Women with abnormal coagulation test results were younger, had earlier onset of disease (as seen by the lower gestational age at onset and delivery), had higher aspartate transaminase levels, and were more often given corticosteroids and magnesium sulphate. There was no difference between groups in the rate of placental abruption.

The relationship between platelet count and the probability of abnormal coagulation, as assessed using a logistic regression model with platelet count fitted as a restricted cubic spline, is shown in Figure. Using this figure, the additional threshold level of a platelet count of $150 \times 10^{9} / \mathrm{L}$ was identified for further analysis.

The rates of abnormal coagulation and adverse maternal outcomes corresponding to various platelet count ranges and the odds of outcome occurrence in each of these groups compared with the reference group $\left(>150 \times 10^{\circ} / \mathrm{L}\right)$ are shown in Table 2 . The odds of abnormal coagulation were significantly increased among women with a platelet count of $<50 \times 10^{9} / \mathrm{L}(\mathrm{OR} 7.79 ; 95 \%$ CI 3.36 to 18.04$)$ and between 50 and $99 \times 10^{9} / \mathrm{L}$ (OR 2.69; 95\% CI 1.44 to 5.02) compared with women whose platelet count was $\geq 150 \times 10^{9} / \mathrm{L}$. Odds of any adverse maternal outcome, and specifically the need for blood transfusion, were also increased with a platelet count $\leq 50 \times 10^{9} / \mathrm{L}$ or between 50 and $99 \times 10^{9} / \mathrm{L}$.

The odds ratios for any adverse maternal outcome or blood transfusion alone were 2.55 (95\% CI 1.55 to 4.19$)$ and 3.77 (95\% CI 1.97 to 7.21 ), respectively in women with 


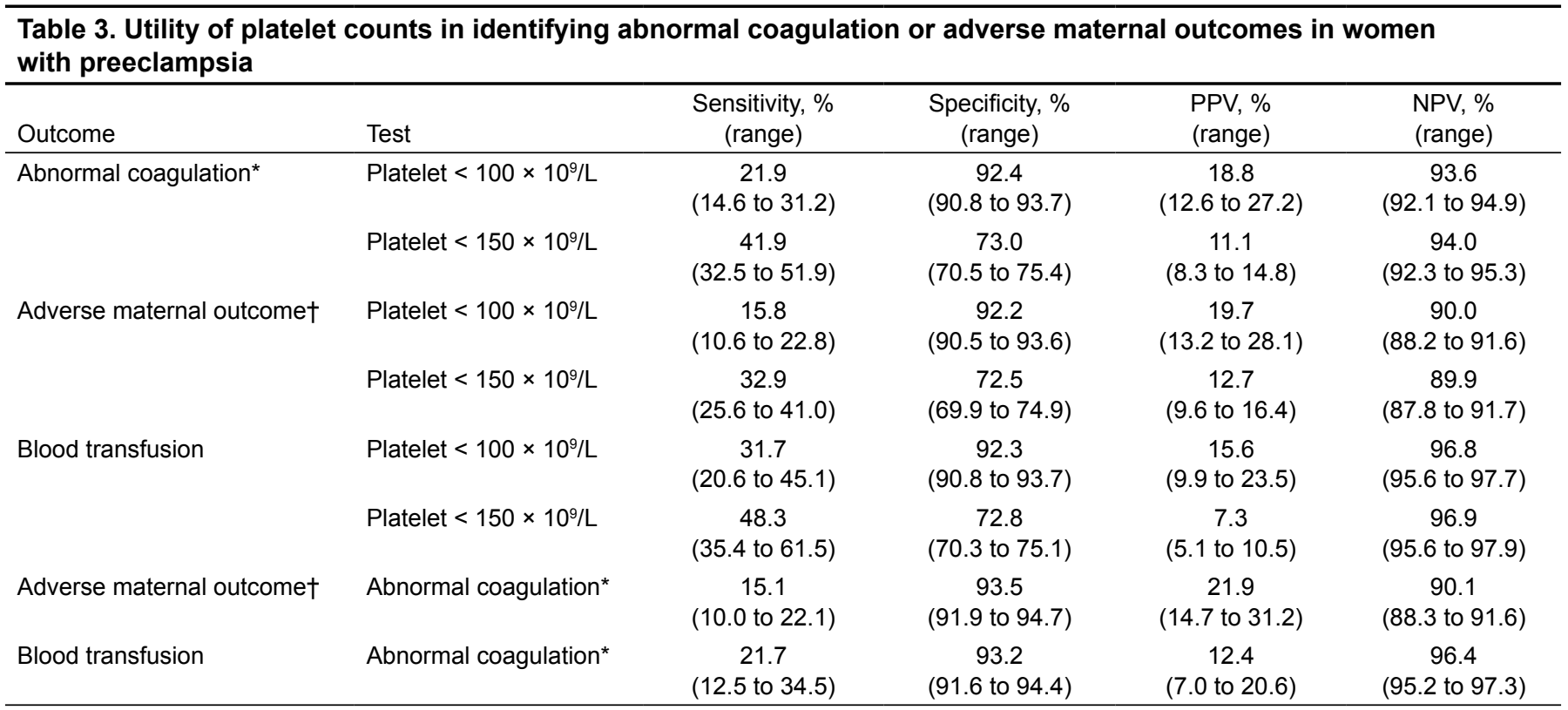

NPV: negative predictive value; PPV: positive predictive value

*Elevated INR and/or decreased fibrinogen, compared with normal third trimester range.

†See text for details.

one or more than one abnormal coagulation test results compared with those with normal coagulation test results.

We performed a sensitivity analysis examining only nonhematological outcomes, and found a significant association between a platelet count $<50 \times 10^{\circ} / \mathrm{L}$ and the outcome (OR 5.68; 95\% CI 1.85 to 17.45). A sensitivity analysis was also performed, grouping cases by diagnosis at enrolment (hypertension and proteinuria or HELLP, hypertension and hyperuricaemia, and superimposed preeclampsia), and a similar association with all outcomes was found (data not shown).

The efficiency of using platelet count thresholds of $100 \times 10^{9} / \mathrm{L}$ and $150 \times 10^{9} / \mathrm{L}$ to identify women with abnormal coagulation, the PIERS combined adverse maternal outcome, or the need for blood transfusion specifically is shown in Table 3, presenting the sensitivity, specificity, positive predictive value, and negative predictive value. The ability of abnormal coagulation test results to predict the PIERS combined adverse maternal outcome or blood transfusion alone is also shown in Table 3. All tests showed negative predictive value and specificity $>90 \%$, but low sensitivity and positive predictive value.

\section{DISCUSSION}

Within our cohort of 1405 women with preeclampsia admitted to tertiary perinatal units, thrombocytopenia, defined by a platelet count $<150 \times 10^{9} / \mathrm{L}$, occurred in 395 women (28.1\%). Abnormal coagulation test results were unusual in the study cohort, occurring in only 105 women $(7.5 \%)$. This is consistent with previous studies and reports. ${ }^{5-7,20-23}$ In addition, platelet counts $<100 \times 10^{9} / \mathrm{L}$ were found to be associated with abnormal coagulation test results. As clinicians would expect, both low platelet counts and abnormal coagulation were associated with an increased risk of adverse maternal outcome(s) or blood transfusion specifically.

Our finding that a platelet count $<100 \times 10^{9} / \mathrm{L}$ was not a sensitive indicator of abnormal coagulation was surprising. Even if a platelet count $<150 \times 10^{9} / \mathrm{L}$ was used as the threshold for a positive test, only $42 \%$ of women with abnormal coagulation would have been correctly identified. It is important to note that of the 1283 women with a platelet count $>100 \times 10^{9} / \mathrm{L}(91.3 \%$ of the study cohort), $82(6.4 \%)$ had the outcome of abnormal coagulation. Although this is significantly less than the rate of abnormal coagulation found in women with platelet counts $<100 \times 10^{9} / \mathrm{L}$ in this population $(18.9 \%)$, it may be clinically significant, given the association found between abnormal coagulation and the adverse maternal outcomes. These results do not fully support the findings of Leduc et al. ${ }^{7}$ who studied 100 women with severe preeclampsia and concluded that abnormal coagulation (defined by low serum fibrinogen or elevated aPTT) was always associated with thrombocytopenia. Other similar 
studies resulted in the same conclusion for women with severe preeclampsia. ${ }^{5,6,22}$ The differences in our results are likely due to our larger sample size and may also have been affected by the inclusion in our cohort of women with mild as well as severe disease.

Defining adequate sensitivity and specificity for a screening test to be used in clinical practice requires that we consider the implications of false-positive or false negative results. ${ }^{24,25}$ In clinical practice, the platelet count is recommended as a screening test in women with hypertension in pregnancy to determine if further tests of coagulation are required. With a high false-negative rate, and consequently low sensitivity, platelet count screening would result in women with abnormal coagulation not being identified before interventions such as Caesarean section or neuraxial anaesthesia. When clinicians are aware of coagulation abnormalities, they will adjust practice to, for example, place an abdominal drain after a Caesarean section or withhold neuraxial anaesthesia. Although we did not have any complications of epidural anaesthesia in our cohort, this is likely because all women had tests of coagulation, beyond the platelet count, performed as part of their routine surveillance.

A high false-positive rate, in this case, would mean more women would undergo further coagulation tests (fibrinogen, aPTT, INR) than necessary, but this would not necessarily affect clinical practice adversely. Having high sensitivity is critical, more so than having high specificity. In our study, neither a cut-off platelet count of $<100 \times 10^{9} / \mathrm{L}$ nor one of $<150 \times 10^{9} / \mathrm{L}$ had great sensitivity for predicting abnormal coagulation. Even if the upper limit of confidence intervals around the point estimates of sensitivity was correct, we would still identify only $30 \%$ to $50 \%$ of women with abnormal coagulation. Given the consequences of a missed positive test, this yield is not adequate.

The situation is similar when considering the use of the platelet count as an independent predictor of adverse maternal outcomes. Failing to identify women who are at great risk of an adverse outcome could result in significant morbidity and possibly even mortality. This is particularly relevant when managing women in rural and remote settings. On the other hand, over-identifying women at risk may lead to unnecessary interventions and, in the case of early onset disease, iatrogenic prematurity and increased risk to the fetus. In this case, both a high sensitivity and high specificity would be required to make a treatment decision.

Using a cut-off platelet count of $<100 \times 10^{9} / \mathrm{L}$ resulted in high specificity when predicting adverse maternal outcomes or blood transfusion alone, but low sensitivity
(16\% for any adverse maternal outcome and 32\% for blood transfusion alone). The high negative predictive value and specificity are likely due to the low incidence of adverse outcomes in the population and are not truly reflective of the efficacy of the test. Similar results were found when abnormal coagulation was used as a predictor of adverse maternal outcomes.

When the efficacy of abnormal coagulation as a predictor of adverse maternal outcomes was compared with platelet count based on sensitivity, specificity, negative predictive value and positive predictive value, we found no difference. This implies that measuring INR or serum fibrinogen does not add any clinical advantage to testing for platelet count alone in these cases. This argument is further strengthened by the results of the fullPIERS model. When coagulation tests and platelet count were evaluated among several other candidate predictor variables for inclusion in the fullPIERS model, platelet count remained in the model, while coagulation tests did not. ${ }^{26}$ The final variables in the fullPIERS model were gestational age at onset of preeclampsia, occurrence of chest pain or dyspnea, oxygen saturation by pulse oximetry, serum creatinine level, platelet count, and aspartate transaminase level. ${ }^{26}$

A limitation of this study is that we did not collect data on the presence of either inherited or acquired thrombophilias in past medical history. This was because in our interim analysis of the first 1250 women in the total PIERS cohort we did not find any relationship between history of thrombophilia and adverse maternal outcome in women who were admitted with preeclampsia. This does not address the issue of whether or not thrombophilias and preeclampsia coaggregate, ${ }^{3}$ but it does suggest that thrombophilias do not add incrementally to the maternal risks of preeclampsia after the diagnosis has been made.

In addition, aPTT results and information on antiphospholipid antibodies were excluded from the definition of abnormal coagulation in this study because they were not uniformly performed on women in the PIERS cohort. Antiphospholipid antibodies have been reported as prevalent $(10 \%$ to $30 \%)$ among women with preeclampsia. ${ }^{27,28}$ Excluding aPTT from our definition of the outcome "abnormal coagulation" was felt to be appropriate because clinicians clearly did not feel it was an important investigation.

A second limitation of the study is that it had only sufficient statistical power to investigate the relationship between platelet count at a single time point and abnormal coagulation test results or need for blood transfusion, taken to be surrogates of the true risk of significant 
hematological complications. Clinicians must also consider the rate of change of platelet counts over time, but we were unable to address this in our study. The PIERS combined adverse maternal outcome is also inadequate as a surrogate marker of hematological complications. Although this combined outcome was rigorously defined for the development of the PIERS models, it reflects outcomes of preeclampsia as a whole, not necessarily specific to hematological complications. The strength of modelling against the PIERS combined outcome in this study is that this reflects the real world clinical concerns associated with preeclampsia.

One strength of this study is that the data come from a large, international database of well-characterized women with rigorously defined preeclampsia. This allowed us to examine each sub-group of preeclampsia. This adds to previous studies in which the relationship between platelet count and abnormal coagulation was observed only in cases of severe preeclampsia, however defined. An additional strength of our study is that, in contrast to previous studies, we also investigated the association between platelet count and adverse maternal outcome, specifically the need for blood transfusion. Beyond identifying risk in order to guide clinical management, coagulation testing is also performed to identify women who may be at risk of epidural hematoma associated with epidural analgesia. In previous studies using thromboelastography to assess the relationship between platelet count and abnormal coagulation, a platelet count $<100 \times 10^{9} / \mathrm{L}$ was associated with hypocoagulation in women with severe preeclampsia. ${ }^{5,29}$ None of the women in these studies who received epidural analgesia had complications. In our population, neuraxial anaesthesia was used in $89.4 \%$ of women with a platelet count $<100 \times 10^{9} / \mathrm{L}$, and no complications, including epidural hematoma, were seen. However, we had no information about the timing of induction of neuraxial anaesthesia in relation to platelet count or the presence of the abnormal coagulation tests. Our findings support the opinion that regional anaesthesia should not be withheld from women solely because of a platelet count $<100 \times 10^{9} /$ L. $^{11}$

\section{CONCLUSION}

This study confirms that, among women admitted to hospital with preeclampsia, there is a significant association between both a platelet count $<100 \times 10^{9} / \mathrm{L}$ and abnormal coagulation test results and an increased risk of adverse maternal outcome, or blood transfusion specifically. While a platelet count $<100 \times 10^{9} / \mathrm{L}$ should alert caregivers to the real possibility of generalized coagulopathy, a normal platelet count alone should not be used as an effective "rule out" test for mild or moderate coagulopathy because of the low sensitivity of this test.

\section{ACKNOWLEDGEMENTS}

This study was supported by operating grants from the Canadian Institutes of Health Research (CIHR) and the UNDP/UNFPA/WHO/World Bank Special Programme of Research, Development and Research Training in Human Reproduction. Salary awards were received from the CIHR (PvD), Michael Smith Foundation for Health Research (LAM, PvD), and Child and Family Research Institute (SL, PvD).

The other members of the PIERS (Pre-eclampsia Integrated Estimate of RiSk) Study Group are Jing Li, Mark Ansermino, Samantha Benton, Naomi Kronitz, Jennifer Menzies, Alexi Millman, Keith Walley, James Russell (Vancouver, BC); Shoo K Lee (Toronto, Ontario); Jean-Marie Moutquin and Annie Ouellet (Sherbrooke, Québec); Graeme Smith (Kingston, Ontario); Andrée Gruslin (Ottawa, Ontario); James Walker (Leeds, UK); Fiona Broughton Pipkin and Pamela Loughna (Nottingham, UK), Philippa Kyle and Peter Moore (Christchurch, NZ); and Barry Walters (Subiaco, Western Australia).

The members of the Delphi consensus were (from Canada) $\mathrm{P}$ von Dadelszen (maternal-fetal medicine $[\mathrm{MFM}]$ ), LA Magee (obstetric internal medicine (OIM)), MJ Douglas (obstetric anaesthesia), KR Walley (critical care medicine [CCM]), JA Russell (CCM), SK Lee (neonatology), A Gruslin (MFM), GN Smith (MFM), AM Côté (OIM), J-M Moutquin (MFM); (from the United States) JM Roberts (MFM); (from the United Kingdom) S Robson (MFM), M de Swiet (OIM), and JJ Walker (MFM and OIM); (from Australia) MA Brown (OIM) and G Davis (MFM); and (from New Zealand) LA McCowan (MFM), P Kyle (MFM), and MP Moore (OIM).

We acknowledge the efforts of the seven PIERS site co-ordinators (Lynn Bissonnette, Sherbrooke, QC; Laura Payant and Svetlana Shachkina, Ottawa, ON; Heather Ramshaw, Kingston, ON; Jane Hayes, Leeds, UK; Barbra Pullar, Christchurch, NZ; and Claire Parker, Subiaco, AU) for their assistance. Thanks to Pamela Lutley, Terry Viczko, Jonathan Lam, and Kelly Richardson for their tremendous help in getting this project underway, and to Yi Lin, Xiang Xuan, and Ying $\mathrm{C} \mathrm{MacNab}$ for their assistance with the preliminary statistical analyses. 


\section{REFERENCES}

1. Hogan MC, Foreman KJ, Naghavi M, Ahn SY, Wang M, Makela SM, et al. Maternal mortality for 181 countries, 1980-2008: a systematic analysis of progress towards Millennium Development Goal 5. Lancet 2010;375:1609-23.

2. Silasi M, Cohen B, Karumanchi SA, Rana S. Abnormal placentation, angiogenic factors, and the pathogenesis of pre-eclampsia. Obstet Gynecol Clin North Am 2010;37:239-53.

3. Steegers EA, von Dadelszen P, Duvekot JJ, Pijnenborg R. Pre-eclampsia. Lancet 2010;376:631-44.

4. von Dadelszen P, Magee LA, Lee SK, Stewart SD, Simone C, Koren G, et al. Activated protein $\mathrm{C}$ in normal human pregnancy and pregnancies complicated by severe pre-eclampsia: a therapeutic opportunity? Crit Care Med 2002;30:1883-92.

5. Sharma SK, Philip J, Whitten CW, Padakandla UB, Landers DF. Assessment of changes in coagulation in parturients with pre-eclampsia using thromboelastography. Anesthesiology 1999;90:385-90.

6. Kramer RL, Izquierdo LA, Gilson GJ, Curet LB, Qualls CR. "Preeclamptic labs" for evaluating hypertension in pregnancy. J Reprod Med 1997;42:223-8.

7. Leduc L, Wheeler JM, Kirshon B, Mitchell P, Cotton DB. Coagulation profile in severe pre-eclampsia. Obstet Gynecol 1992;79:14-8.

8. Magee LA, Helewa ME, Moutquin JM, von Dadelszen P, Cardew C, Cote AM, et al. Diagnosis, evaluation and management of the hypertensive disorders of pregnancy. SOGC Clinical Practice Guidelines, No. 206, March 2008. J Obstet Gynaecol Can 2008;30(3 Suppl 1):S1-S48.

9. Menzies J, Magee LA, Li J, MacNab YC, Yin R, Stuart H, et al. Instituting surveillance guidelines and adverse outcomes in pre-eclampsia. Obstet Gynecol 2007;110:121-7.

10. von Dadelszen P, Sawchuck D, McMaster R, Douglas MJ, Lee SK, Saunders $\mathrm{S}$, et al. The active implementation of pregnancy hypertension guidelines in British Columbia. Obstet Gynecol 2010;116:659-66.

11. Gogarten W. Pre-eclampsia and anaesthesia. Curr Opin Anaesth 2009;22:347-51

12. von Dadelszen P, Payne B, Li J, Ansermino JM, Broughton-Pipkin F, Cote AM, et al. Predicting adverse maternal outcomes in pre-eclampsia: the fullPIERS model—development and validation. Lancet 2011;377:185-6.

13. Barton JR, O’Brien JM, Bergauer NK, Jacques DL, Sibai BM. Mild gestational hypertension remote from term: progression and outcome. Am J Obstet Gynecol 2001;184:979-83.

14. Homer CS, Brown MA, Mangos G, Davis GK. Non-proteinuric pre-eclampsia: a novel risk indicator in women with gestational hypertension. J Hypertens 2008;26:295-302.
15. Sibai BM, Stella CL. Diagnosis and management of atypical pre-eclampsia-eclampsia. Am J Obstet Gynecol 2009;200:481.e1-481.e7.

16. Milholland AV, Wheeler SG, Heieck JJ. Medical assessment by a Delphi group opinion technic. N Engl J Med 1973;288:1272-5.

17. Hutchinson A, Fowler P. Outcome measures for primary health-care: what are the research priorities? Br J Gen Pract 1992;42:227-31.

18. Bellomo R, Kellum JA, Ronco C. Defining and classifying acute renal failure: from advocacy to consensus and validation of the RIFLE criteria. Intensive Care Med 2007;33:409-13.

19. PIERS Project Resource. Full definitions of maternal adverse outcomes. Prediction of adverse maternal outcomes in pre-eclampsia: development and validation of the fullPIERS model. Available at: http://piers.cfri.ca/Resources.aspx. Accessed July 7, 2011.

20. Valera M, Parant O, Vayssiere C, Arnal J, Payrastre B. Physiologic and pathologic changes of platelets in pregnancy. Platelets 2010;21:587-95.

21. Prieto JA, Mastrobattista JM, Blanco JD. Coagulation studies in patients with marked thrombocytopenia due to severe pre-eclampsia. Am J Perinatol 1995;12:220-2.

22. Barron WM, Heckerling P, Hibbard JU, Fisher S. Reducing unnecessary coagulation testing in hypertensive disorders of pregnancy. Obstet Gynecol 1999;94:364-70.

23. Harlow FH, Brown MA, Brighton TA, Smith SL, Trickett AE, Kwan YL, et al. Platelet activation in the hypertensive disorders of pregnancy. Am J Obstet Gynecol 2002;187:688-95.

24. Bewick V, Cheek L, Ball J. Statistics review 14: logistic regression. Crit Care 2005;9:112-8.

25. Anderson RP, Jin RY, Grunkemeier GL. Understanding logistic regression analysis in clinical reports: an introduction. Ann Thorac Surg 2003;75:753-7.

26. von Dadelszen P, Payne B, Li J, Ansermino JM, Pipkin FB, Cote AM, et al. Prediction of adverse maternal outcomes in pre-eclampsia: development and validation of the fullPIERS model. Lancet 2011;377:219-27.

27. Saha SP, Bhattacharjee N, Ganguli RP, Sil S, Patra KK, Sengupta M, et al. Prevalence and significance of antiphospholipid antibodies in selected at-risk obstetrics cases: a comparative prospective study. J Obstet Gynaecol 2009;29:614-8.

28. Romero R, Mazor M, Lockwood CJ, Emamian M, Belanger KP, Hobbins JC, et al. Clinical significance, prevalence, and natural history of thrombocytopenia in pregnancy-induced hypertension. Am J Perinatol 1989;6:32-8.

29. Orlikowski CEP, Rocke DA, Murray WB, Gouws E, Moodley J, Kenoyer DG, et al. Thrombelastography changes in pre-eclampsia and eclampsia. Br J Anaesth 1996;77:157-61. 